\title{
"It's Second Nature": Sustaining Public Engagements with Addressing Climate Change at the Community Level
}

\author{
STEPHEN AXON
}

School of Natural Sciences and Psychology, Liverpool John Moores University, James

Parsons Building, Liverpool, L3 3AF

Email: S.J.Axon@ljmu.ac.uk | Tel: 01519046331

Volume 4, 2016

http://dx.doi.org/10.3998/mjs.12333712.0004.006

\section{ABSTRACT}

Whilst the number of studies focusing on strategies to engage the public with addressing climate change and sustainability are growing exponentially, little attention has been paid to the (multiple) ways in which individuals wish (or do not wish) to become involved, and to what extent. This is striking given that research indicates that community-based carbon reduction strategies struggle to turn initial excitement into sustained participation. This is a significant barrier to grassroots projects that need to be scaled up to address climate change on a wider scale. With reference to fieldwork carried out in the United Kingdom employing focus groups, this paper reports that individuals are willing to actively participate in public engagement activities and become involved (on a number of cognitive, affective and behavioural levels) with community-based projects that address climate change. In so doing, this paper illustrates that people want to take ownership and responsibility for sustainability in their communities. However, this transition towards sustainable living needs to be achieved in ways in which that stimulates (sustained) engagement. This paper is of particular relevance for academics and practicing communities in sustainability, demonstrating that higher levels of engagement with communitybased carbon reduction strategies indicates a shift towards higher rungs of citizen participation in local sustainable development. The result of higher citizen involve- 
ment in local sustainability demonstrates a changing climate in the co-production, co-governance and co-delivery of a low-carbon sustainable future.

\section{Introduction: Climate change, sustainability and community-based carbon reduction}

The impacts and challenges that the physical and human environments face as a result of anthropogenic-forced global environmental change are, by now, familiar. The impetus for reducing carbon emissions is real and present, but its translation into action lacks immediacy and severity (Haxeltine and Seyfang 2009). The IPCC have repeatedly called for governments, businesses and communities to tackle the dual challenge of addressing climate change: mitigation and adaptation. Given that actions mitigating and adapting to the consequences of a changing climate are closely related to political orientation (McCright 2011) and current lifestyles (Roy and Pal 2011), addressing climate change is a very contentious issue. To date there is little agreement about the "most effective strategies for achieving a transition through behaviour change" (Moloney et al. 2010, 7615). Yet central to much of the climate change debate is the consensus that changes to human actions are required to transition towards sustainable low-carbon lifestyles.

While many of the primary effects of climate change may be global, the causes are located within the activities and climate-relevant behaviours of individuals, households and communities (Whitmarsh and O'Neill 2011). Previous attempts to change individual behaviour have utilised economic incentives, persuasion campaigns and education programmes with limited success (Abrahamse et al. 2005; Barr et al. 2011; Kennedy 2010; Verplanken 2011; Whitmarsh and Lorenzoni, 2010; Winter 2010). These attempts assume that individuals fully control their behaviour and make decisions in isolation, however this is not the case (Heiskanen et al. 2011; Jackson 2005). Research in environmental psychology, communication and sociology suggests that people's identities and affiliations with social groups affect their engagement with environmental issues and are strong predictors of environmental behaviour (Ajzen 1991; Stern and Dietz 1999). Overcoming the barriers faced previously in behaviour change programmes, studies have focused on aligning descriptive norms (what people typically do) with injunctive norms (what people approve or disapprove) to environmental communications and the influence social norms exert on behaviour (Bratt 1999; Cialdini 2003).

In recent years there has been (global) exponential growth in the number of 
community responses towards the challenges of climate change and sustainability (Axon In Press). Community level initiatives hold the potential to ground climate change policy and action in a much more visible way to the everyday practicalities of energy use and lifestyle choices than more 'top-down' measures have been able to change (Ockwell et al. 2009). Community-based social marketing (CBSM) focuses upon removing barriers to behaviour change while concurrently promoting benefits of change (Kennedy 2010). CBSM achieves this by seeking commitments from participants, offering prompts as mental cues, using incentives, using credible communication strategies and reinforcing norms (Abrahamse et al. 2005; Kennedy 2010). These interventions have been applied in communities and have shown to positively influence individual environmental behaviours norms (Abrahamse et al. 2005; Kennedy 2010). These assertions validate the application of behavioural change initiatives tailored towards the community level.

Community-based carbon reduction strategies (CBCRS) are one example of action towards achieving local sustainable development, addressing climate change and facilitate sustainable living (Alexander et al. 2007; Middlemiss 2011; Middlemiss and Parrish 2010). CBCRS bring citizens together to act collectively in creative ways on climate and local sustainability issues (Heiskanen et al. 2010; Mulugeeta et al. 2010). This paper defines CBCRS as a network of organisations and residents working in collaboration aiming to reduce domestic and whole-community carbon emissions in the local community through changing behaviour and using green technologies to facilitate, increase and maintain sustainable low-carbon lifestyles. This definition takes into account the number of stakeholders involved in the organisation, and delivery, of community-based carbon reduction. The definition highlights the diversity of interventions that change behaviour and application of small-scale technical solutions in the short, medium and long term that fit firmly within broader notions of sustainable living (Middlemiss 2011).

For sustainable lifestyles to become the norm within society, they must be enabled and encouraged by the socio-technical systems and institutions that surround us (Geels 2002; Geels and Schot 2007). CBCRS are an ideal approach to facilitate and maintain the uptake of sustainable lifestyles and frame decision-making and actions within the context of local communities utilising multiple interventions to do so (Abrahamse et al. 2005; Axon 2015). Exemplifying CBCRS, the Transition Towns Network is a collection of towns, cities and states that seek to reduce emissions and adapt to the consequences of climate change (Aitken 2012; Feola and Nunes 2014; Hopkins 2008). CBCRS demonstrate that actions are cost effective with greater emissions reductions being possible, foster cohesive and resilient com- 
munities, and residents are involved in the low-carbon future of their communities (Barr and Devine-Wright 2012; Middlemiss and Parrish 2010). The exponential growth of CBCRS in recent years could play a significant role in climate stabilisation efforts if scaled-up (Axon In Press; Dietz et al. 2009; Geels and Schot 2007; Seyfang, 2010). Characterised as niches of innovative opportunities, CBCRS experiment with new practices that have the potential for wider social transformation (Middlemiss and Parrish 2010; Seyfang 2010; Seyfang et al. 2014).

Yet there are drawbacks of community responses including feelings of intimidation on behalf of residents feeling pressured to participate, lack of awareness about how such projects positively impact on climate change, and sustaining participation beyond initial excitement (Alexander et al. 2007; Axon 2015; Feola and Nunes 2014). Lack of funding to support community initiatives, volunteers facing 'burn out' and lack of overall strategic and financial direction substantially impact upon the efficacy of CBCRS to deliver their overall aim and activities (Feola and Nunes 2014). Significant drawbacks are visible in communities where sustainable alternatives are not available, thus limiting actions that can be taken (Axon In Press). The challenge that CBCRS face to effectively fulfil their role for wider social transformation lies with meaningfully, and continuously, engaging the public with addressing climate change.

Public engagement is vital and already evident in CBCRS, pioneering social innovations for addressing climate change that demonstrate real-world experiments with low-carbon sustainable living in communities (Alexander et al. 2007; Middlemiss 2011). Engaging the public with addressing climate change is not an option but an imperative (Wolf and Moser 2011). Engagement has been defined as "a personal state of connection with the issue of climate change, in contrast to engagement solely as a process of public participation in policy making" (Wolf and Moser 2011, 550). Engagement has three key components: cognitive (knowledge/understanding), affective (emotion/interest and concern) and behavioural (action) (Lorenzoni et al. 2007; Ockwell et al. 2009; Whitmarsh and O'Neill 2011; Wolf and Moser 2011). Therefore engagement, in this respect towards CBCRS, encompasses what people know, feel and do (Whitmarsh et al. 2013). Applying this theoretical framework to CBCRS, cognition reflects what individuals understand to be the aims of the project, its activities (or events) and how they can become involved in such a project. Affective engagements refer to interests and emotions that are similar or different with CBCRS. These emotions may be positive, indifferent or negative towards different elements of a project such as its organisation, delivery or activities 
to get individuals involved. Affective engagements often reflect very diverse evaluative and considered emotions towards different aspects of CBCRS that do not always appear to be articulated as an emotion but an extensive of cognitive engagements. Indicators of affect lie within the language used by residents that determine their emotional responses (Besnier 1990). Behavioural engagements reflect the different types of actions individuals may be able to participate in (depending upon the project itself). Pledging commitments, participating in meetings, volunteering or coordinating community events are some examples of behavioural engagements with CBCRS. Wolf and Moser (2011) state that much research remains to be undertaken in how to increase, balance, effectively motivate, and sustainably engage on all facets of engagement.

This implies that public engagement with addressing climate change fluctuates with time and that individuals' engagement needs to be facilitated in the short term and sustained in the long term. From these perspectives, CBCRS have the potential to effectively engage the public with addressing climate change supported with interventions aimed at sustaining participation. There are substantial challenges that inhibit a simple transition; principally, the difficulty in turning initial excitement in such projects to sustained engagement (Alexander et al. 2007). Engagement theories are a relatively new approach to exploring peoples' responses to a range of issues (Krause and Coates 2008; Whitmarsh and O'Neill 2011; Whitmarsh et al. 2011). These techniques have demonstrable merit in helping to understand responses towards complex issues, such as addressing climate change, but have not yet been applied to engagements with CBCRS (Axon 2015). Engagement theories place substantial emphasis on the interrelated engagements individuals have with CBCRS that other theoretical frameworks such as social practice theories overlook. No studies have, until now, addressed this important research gap and practicebased issue given that sustained participation in CBCRS is required if such projects are to become more acceptable for wider social transformation as part of the multilevel perspective nested hierarchy proposed by Geels (2002). Where previous studies have applied social practice approaches, by employing engagements theories to the methodological frame of the study this paper contributes new understandings of how the public are (or are not) engaged with CBCRS. Illuminating the specific character of individual engagements with CBCRS, this study focuses on three interrelated elements of engagement that can be influenced to sustain participation with addressing climate change at the community level. 


\section{Methodological Approaches}

The aims of this research were to investigate the diverse attitudes towards addressing climate change and the (multiple) ways in which individuals wish (or do not wish) to become involved in CBCRS, and to what extent. Three suburban communities in the UK (Blacon in Chester; Congleton in Cheshire; and Northwood in Staffordshire) were chosen to explore themes around attitudes and actions towards addressing climate change; factors supporting or impeding action towards sustainable living; and engagements with CBCRS. Internationally, the investigation of the factors influencing the development and governance of, and engagements with, CBCRS is currently an under-researched area of investigation (Seyfang et al. 2014; Whitmarsh et al. 2013). Previous research on low-carbon transitions has not yet sought to address how engagement with CBCRS can be sustained and has instead sought to focus on the governance of urban climate change experiments and the political dimensions of regional development (Castan Broto and Bulkeley 2013; While et al. 2010). This research gap is surprising given that these areas of research can illuminate what it means for individuals to become involved in such projects and how participation in a low-carbon future can be facilitated, increased and sustained. In order to begin addressing this research gap, a mixed methodological approach was identified as providing sufficient breadth and depth of detail (Bryman 2008; Newing 2011) towards illuminating key understandings around the extent to, and ways in, which individuals engage with addressing climate change in their communities.

To achieve a fuller understanding of individual engagements with CBCRS, this research required the "real words" (Wisker 2001, 168) of residents and direct access to relevant conversation. Focus groups were conducted in late 2013 to explore more deeply the character of individual engagements with CBCRS. A total of 4 focus groups were held: 1 in Blacon; 1 in Congleton; and 2 in Northwood. To provide a balanced overview of qualitative data, it was decided that two focus groups be held in communities with an established CBCRS and a further two focus groups without such projects. In total, 17 participants discussed their views towards addressing climate change and sustainable living with the facilitator between 45 minutes and an hour and a half. Each focus group was recorded, transcribed and analysed as part of a thematic analysis approach (Braun and Clarke 2006; Savin Baden and Howell Major 2013). Participants in the focus groups for all three communities surveyed were allocated a number using the following system e.g. BP1 (Blacon Participant 1); CP4 (Congleton Participant 4); and NP7 (Northwood Participant 7). Focus groups were applied in this research as they generate valuable emotional and sub- 
Table 1: Socio-demographic characteristics of participants

\begin{tabular}{lllll}
\hline Location & Participant Number & Gender & Age & Occupation \\
\hline Blacon & BP1 & Male & 24 & Hospital Porter \\
& BP2 & Male & 24 & Administrator \\
& BP3 & Female & 24 & Teacher \\
& BP4 & Female & 24 & Nursery Nurse \\
& CP1 & Female & 46 & Health Visitor \\
& CP2 & Male & 76 & Retired \\
& CP3 & Female & 74 & Retired \\
& CP4 & Female & 23 & Primary Teacher \\
& CP5 & Male & 47 & Project Engineer \\
& NP1 & Male & 50 & Air Ambulance \\
& & & & Paramedic \\
& NP2 & Female & 41 & School Nursing Sister \\
& NP3 & Female & 53 & Nurse \\
& NP4 & Female & 20 & Student \\
& NP5 & Male & 27 & Support Worker \\
& NP6 & Male & 53 & Office Manager \\
& NP7 & Female & 23 & Retail Assistant \\
& NP8 & Male & 30 & Logistics Manager \\
\hline
\end{tabular}

jective responses and multilayered vocality (Morgan 1997; Newing 2011), and can provide possibilities for exploring the gap between what people say and what they do (Conradson 2005). This methodological approach is, therefore, well placed to identify and illuminate key themes that arise from the well-identified 'value-action gap' in climate change attitudes and behaviours (Blake 1999; Kollmuss and Agyeman 2002).

While the findings here originate from UK residents, the results of the focus groups have international applicability in terms of highlighting, and responding to, various positionalities on addressing climate change at the community level. These findings show that such activities have strong, and often multifaceted, practice elements. The outcomes of this study illuminates issues that are transferable to other localities globally that have diverse social and political contexts and warrant further investigation. The subject of addressing climate change and sustainable living at a local level was predicated on strong notions of (collective) activity. Whilst making an original academic contribution to environmental social science, policymakers and practitioners will find these results to be of particular interest as this paper highlights how community-based activities seeking to facilitate, increase and maintain actions to address climate change and transition to sustainable forms of low-carbon living can be supported effectively and meaningfully. 


\section{Results and Discussion}

Participants provided substantial information regarding their (potential) engagement with CBCRS in a number of ways: (1) cognitively (what CBCRS individuals are aware of and associated understandings); (2) affectively (positive, indifferent and negative emotional connections); (3) behaviourally (willingness to participate and identified methods of participation); and (4) identified previous engagements. Cognitive engagements are exemplified in the following statements:

"I'm not aware of any in my area. If there were one I think I would be happy to get involved" (BP4),

"It makes the environment look nicer and would create more of a feel good factor for your local community" (BP3),

"Collectively working together means you'll have a bigger impact. Surely this is the future? Living in a more sustainable way, it's second nature" (NP3),

"It depends on how many people do it though, because there's no point in having something in your local area if no ones going to go and take an interest in doing something about it" (NP7).

These comments indicated that while participants were not aware of any formal projects (despite projects existing in two areas), individuals did suggest they would be inclined to become involved and that participation in CBCRS does result in positive outcomes, personally and for the environment. Furthermore, residents suggested that such community approaches are seen in a number of ways, as; methods that can support the transition towards sustainable living; communal approaches that generate numerous social and environmental benefits. This indicates that there are multiple motivations for involvement that are predicated on personal satisfaction of living more sustainably to the outcomes of participation. In this example, participation in CBCRS may foster both intent and impact oriented action (Whitmarsh 2009). Willingness to participate in CBCRS was dependent on the activities of the project itself. This may be the result of a lack of awareness among residents. Practicing communities should therefore seek to continually raise awareness of the activities of CBCRS. Without doing so could render such projects 'invisible', as continually (re)engaging both participating and nonparticipating residents in creative ways sustains involvement. While no negative connotations of community approaches were identified, respondents questioned the role of other individuals in the (broader) transition to sustainability. 
Cognitive engagements also reflected notions of collective action and (non) participation reflecting the idea that a minority cannot sustain participation and success of a project. While the value of CBCRS reflect the ability to harness the creative energies of communities to address climate change in context-specific ways, participants indicated that a project can only be successful if participation is sustained. This point directly reflects turning initial excitement into sustained participation indicated by Alexander et al. (2007). Collective action was a substantial theme throughout this study, reflecting notions of the socially grounded nature of behavior and social norms (Jackson 2005; Kennedy 2010). This suggests that the ways in which participants view CBCRS corresponds with the definition offered in this paper indicating that greater numbers of residents acting together will result in wider benefits of participation (Heiskanen et al. 2010; Mulugeeta et al. 2010). Parkhill et al. (2015) found that collective social action in community-led energy initiatives are essential components for civic engagement. Given that individuals often feel powerless to address climate change reinforcing the collective action and participants

The comments highlighted by residents suggest that CBCRS are (1) inclusive approaches; (2) projects that have impact (socially, economically and environmentally); and (3) influencing the ways in which people feel towards their lifestyle and community. These notions represent the values attributed to CBCRS; which policymakers and practicing communities should demonstrate these to the individuals they seek to engage. Yet NP7 notes that affective engagements are vital to participation; particularly interest, as activities of CBCRS need to be congruent with concerns or motivations of residents. Practicing communities should therefore seek to facilitate and maintain interest through supporting activities and events that relate to how residents wish to be engaged with community-based sustainability. Such comments place emphasis on the role of affective engagements in sustaining participation. In this study, affective engagements are exemplified as follows:

"They're a good idea to get people involved together and the more people involved, the more impact you have" (BP1),

"I love grow[ing] vegs" (CP1),

"I don't know really. I'm not sure. I'd have to see what it's like first" (NP7),

"You might get a few people who try to do it for the benefits and not do anything" (BP2),

"It depends on the outcome, if you just sit around all day and not do nothing then what's the point. It's got to be something people can get out of it" (CP5). 
Affective engagements reflected a number of positionalities towards engaging with CBCRS. Positive affective engagements reflected the values of CBCRS; concepts of communal action; and activities that resonate with individual interests. Again, individuals note how grounding sustainable living practices within communities is advantageous; indicating that participants are aware of the impact of others on their behavior (Jackson 2005). Yet indifferent responses suggested hesitance among participants, considering that potential participation depended upon the activities of the project itself. Some forms of nonparticipation and ambivalence, however articulated, can be related to Foucauldian notions of resistance; indicating a level of opposition (Medina 2011) towards addressing climate change. However these comments genuinely consider the local project rather than the politics of climate change. Participants' negative responses did not object to the concept of CBCRS, rather the quantity and/or quality of action taken. Furthermore, participants suggested that while a project has to be beneficial, the quote by BP2 indicates that residents should contribute in some way. While not being specific, this could relate to taking action to live (more) sustainably or volunteering to lead aspects of a project. These notions of contributing to CBCRS reflect how residents can use their skills in supporting local transitions to sustainable living (Seyfang 2010). This is of particular importance for practicing communities as residents feel that regular, impactful activity is an essential component of CBCRS. Here, practicing communities should support events and actions that resonant with residents while promoting the multifaceted advantages of participation that are intimately linked with affective engagements. Behavioural engagements reflected individuals' willingness, and methods of, participation that are exemplified in the following statements:

"I would like to take part" (NP2),

"It depended on the scheme really, what they introduced" (NP3),

"It would be nice for the community to get involved but I think it's very idealistic" (CP1),

"So much can be done online. Maybe [a] newsletter might work for certain people and social media would work as well" (BP3),

"I used to be involved in a community project. Without being a part of that, you feel quite disconnected from the issues you're concerned with” (BP2).

The majority of focus group participants indicated they would like to become involved in CBCRS, with the remainder indicating a level of hesitancy suggesting that they required more information on the project and its activities before 
participating. This suggests the existence of an "awareness-involvement gap" where limited, or no, understanding about CBCRS and its activities results in uncertainty about whether, and how, to participate in such projects. This barrier presents a number of implications for meaningfully engaging the public with addressing climate change, yet practicing communities should address this through continually seeking to raise awareness; develop creative and stimulating activities; and support residents that wish to participate in whichever ways they want to be (Table 2). This includes engaging nonparticipants and supporting new involvement; increasing regular participants to take more action; and (re)engaging those who may not be as active as previously. This places residents at the heart of CBCRS with realistic expectations that such projects are both proactive and reactive to levels of public engagement that ultimately determine their success. The findings in Table 2 from questionnaire respondents support the identification of this gap. While $49 \%$ identify some method of participation, $20 \%$ are unsure of their prospective (non)participation. Awareness of the existence of this gap for practicing communities indicates that interventions can be applied to counter its impacts and engage residents in meaningful ways; whether through generic awareness raising, tailored information, activities and events, and feedback (Abrahamse et al. 2005).

\section{Illuminating public engagements with community-based carbon reduction}

The statements exemplified in this article indicate that people expend varying levels of cognitive, affective and behavioural engagement towards CBCRS (see Figure 1). The opinions of the individuals provided in this article illuminate the multiple ways in, and extent to, which they would become involved in a community-approach addressing climate change. The value of these perspectives illustrates what addressing climate change in the communities of individual's means to those that reside there. Policymakers and practitioners should learn to respect these perspectives if the public is to be meaningfully engaged with a low-carbon future. Findings presented here reinforce that such engagements do not influence each other in a linear fashion (Whitmarsh and O'Neill 2011), yet indicate the intricate and complex ways in which people comprehend, articulate, and respond to community-based sustainability. Therefore, to sustain participation in CBCRS in meaningful ways "it is not enough to simply know about climate change ... [but] also . . . care about it, be motivated by it and able to take action" (Lorenzoni et al. 2007, 446). This quote by Lorenzoni et al. (2007) is important, and reinforces the paradigm in Figure 1. In 


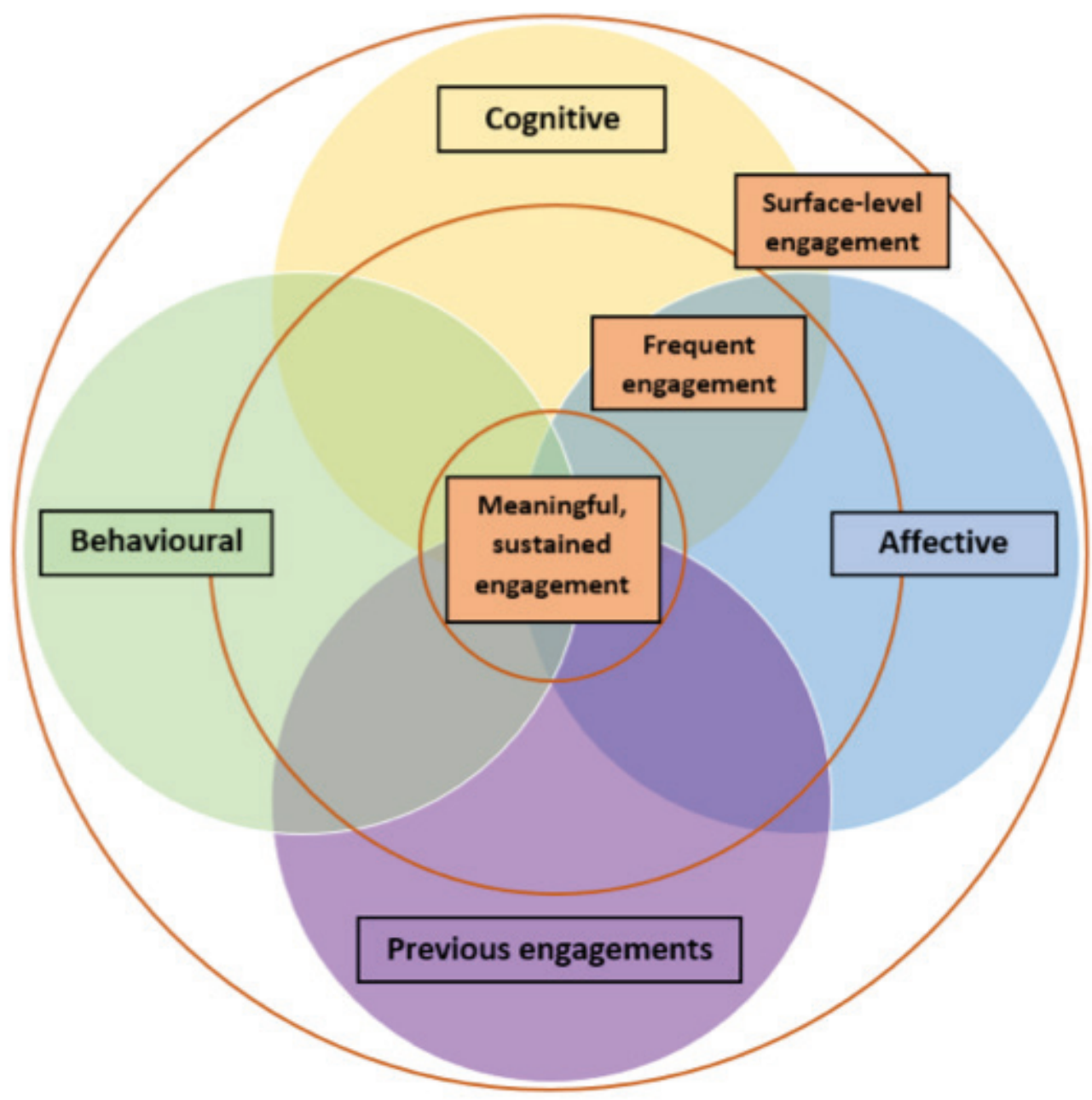

Figure 1: Engagements with community-based carbon reduction strategies

order to take action, individuals must be aware of the action they can take, are able to take and be supported in taking that action. Consequently, there is a need for continuous support (interventions such as tailored information or feedback) to enable such action (Abrahamse et al. 2005). This is a role that practicing communities should be prepared for if such projects are to be successful in engaging the public with addressing climate change at the community level. 


\section{The value of engaging with research}

Focus group participants also added additional comments. In these examples, participants provided their views towards feeling engaged and their ability to articulate their perspectives in a focus group forum, indicating that they wished to be engaged by those implementing such practices more frequently:

"How often do we have the platform for this discussion? It's only now and again that you're going to sit and reflect about what you personally do which I probably wouldn't have done if I hadn't joined in a focus group today. It's getting people to have this action and have these discussions and I think that's the local council's initiatives and they should be trying to get some more focus groups and awareness raising really" (NP2).

Participants stated that focus groups allowed individuals to reflect upon and discuss environmental issues such as addressing climate change and CBCRS within a constructive forum that allows for genuine engagement, illustrating the importance of engaging with research regarding sustainability. These comments indicate that participants have much to say about addressing climate change at the community level and, in turn, want to be heard. By discussing their perspectives and taking on board suggestions from local residents, regular forums allow members of a community to state their own needs and values whilst permitting them to participate in decisions that directly influence the direction of CBCRS (Arnstein 1969; Mannarini 2011; Mulugeeta et al. 2010; Wiesenfeld and Sanchez 2002). This will help to bridge the public-policy-practice divide in addressing sustainability and climate change issues. Participants asked multiple questions themselves and considered that they would feel reassured that their carbon reduction practices were having an impact if they could be provided with tailored information:

"Is this just a drop in the ocean and is it making a difference? Who can give me the evidence and the research that what we are doing is of any consequence that is making any impact for the long term for the next generation" (NP2).

Again, participants identify that the role of CBCRS could provide answers to questions, queries or provide reassurance that their activities are having a positive impact to address climate change. These findings indicate that residents find specific interventions supporting community-based activities to be advantageous in living 
sustainably. This finding is of particular relevance to practicing communities, which outlines the interventions that are known to meaningfully engage individuals with carbon reduction practices (Abrahamse et al. 2005) with those that residents want to support them. This finding therefore bridges the gap between theoretical and practical understandings and applications of supporting participation in CBCRS.

This provides a substantial opportunity for policymakers and practitioners to involve the public with higher levels of community engagement with the ways in which they want to address climate change. For policymakers and practitioners this provides an opportunity for genuine community engagement and involvement with addressing climate change and sustainability without notions of external organisations attempting to take control of community-based projects. Insofar as possible such projects should be community-led. This generates higher forms of community involvement that goes beyond tokenistic forms of participation towards more delegated power where community members control specific areas of the project (Arnstein 1969; Morrison and Dearden 2013; Rogers et al. 2008). Yet, this distinction also allows for CBCRS to be truly owned by local residents where they hold the majority of power and responsibility. This allows sustainability-based practices to be integrated within the community in ways that are meaningful to local people, achieved in ways that are more acceptable to residents (even among those who may initially be against such action), with the flexibility and openness to undertake activities residents wish to be involved with. These issues overcome problematic concerns by practitioners noting that external control and organized activities can often lead to false engagement or short-term participation.

\section{Conclusions: Moving towards new engagements with addressing climate change}

This study addresses the principal research issue around sustaining participation in CBCRS that go beyond initial excitement reported in other studies (Alexander et al. 2007; Feola and Nunes 2014). Whilst providing a unique perspective towards addressing climate change and sustainable living these findings contribute substantive value to the discipline of environmental social science. This paper provides practitioners with new directions to meaningfully engage the public with addressing climate change, as outlined in the discussion. These projects need to be supported by researchers, policymakers and practitioners. This should be done in the following ways: (1) barriers to action should be removed and replaced with enablers of 
action; (2) interventions should be provided continuously and focus on successfully supporting those taking action if CBCRS are to be successful, both in the short and long term; and (3) residents in communities should be encouraged to take responsibility for their local project providing a tailored approach that responds to the needs of the community. These recommendations have the potential to address the issue of how to turn initial excitement in CBCRS to sustained participation (Alexander et al. 2007), leading to higher citizen participation in the co-delivery of a low-carbon sustainable future.

The findings in this paper provide valuable insights into the ways in which individuals conceptualise, and respond to, addressing climate change and sustainable living in their own communities. While these are powerful sentiments demonstrating a variety of positionalities (positive, indifferent and negative positions), they are valuable to policymakers and practitioners who want to engage and involve the public with addressing climate change. Indeed, these ways should match with residents' notions of sustainable living to facilitate and sustain (further) action over time. Without continuously doing so jeopardises catalysing on the natural momentum that people in their communities seek to foster towards (community-based) sustainability. These findings suggest that people want to take ownership and responsibility for sustainability in their communities with a transition towards sustainable living is done in meaningful ways that stimulates (sustained) engagement. This indicates a preference for, and an important shift towards, higher rungs of citizen participation in local sustainable development. This approach provides a true grassroots approach that is tailored to the needs of communities within a broad sustainability agenda (Alexander et al. 2007; Seyfang et al. 2014).

CBCRS are well placed to overcome criticisms that are often directed towards sustainability related projects such as resolving the "value-action gap" (Blake 1999; Kollmuss and Agyeman 2008; Owens and Drifill 2008) and able to meaningfully ground sustainable living within everyday practices. In so doing, residents can (1) have the opportunity to share experiences of sustainable living in their own communities; (2) discover and learn new sustainable ways of living, working, playing, and travelling; and (3) identify what enables, and prevents, them from living sustainably (and address these issues in ways residents find acceptable and meaningful to support sustained engagement). CBCRS can engage with residents inclusively, proactively, constructively, meaningfully and continuously by involving all community members in multiple acts of participation that include strategic and financial governance of the project, rather than tokenistic involvement (Arnstein 1969; Morrison and Dearden 2013). Yet there are also substantial drawbacks and implications that 
need to be taken into account including residents feeling intimidated to participate and ensuring sustainable alternatives are accessible (Alexander et al. 2007; Axon 2015; Feola and Nunes 2014).

\section{Acknowledgements}

The author would like to thank the participants who took part in this study and to the four anonymous reviewers for their comments on earlier drafts of this paper.

\section{References}

Abrahamse, W., Steg, L., Vlek, C. and Rothengatter, T. 2005. "A review of intervention studies aimed at household energy conservation." Journal of Environmental Psychology 25: 273-291.

Aitken, G. 2012. "Community Transitions to Low Carbon Futures in the Transition Towns Network." Geography Compass 6: 89-99.

Aitken, C., Chapman, R. and McClure, J. 2011. "Climate change, powerlessness and the commons dilemma: Assessing New Zealanders' preparedness to act." Global Environmental Change 21: 752-760.

Ajzen, I. 1991. "The Theory of Planned Behaviour." Organisational Behaviour and Human Decision Processes 50: 179-211.

Alexander, R., Hope, M. and Degg, M. 2007. "Mainstreaming Sustainable Development - A Case Study: Ashton Hayes is going Carbon Neutral." Local Economy,22: 62-74.

Arnstein, S. R. 1969. "A ladder of citizen participation." Journal of the American Institute of Planners 35: 216-224.

Axon, S. 2015. Addressing climate change at the community level: Opportunities for, and challenges to, mainstreaming sustainable development, Unpublished PhD Thesis, University of Liverpool.

Axon, S. In Press. "Sustaining public engagement with addressing climate change and the role of social solutions", International Journal of Sustainable Society

Barr, S. and Devine-Wright, P. 2012. "Resilient Communities: sustainabilities in transition." Local Environment 17: 525-532.

Besnier, N. 1990. "Language and affect." Annual Review of Anthropology 19: 419-451.

Blake, J. 1999. "Overcoming the 'Value-Action Gap' in environmental policy: Tensions between national policy and local experience." Local Environment 4: 257-278.

Bratt, C. 1999. "The impact of norms and assumed consequences on recycling behaviour." Environment and Behaviour 31: 630-656.

Braun, V. and Clarke, V. 2006. "Using thematic analysis in psychology." Qualitative Research in Psychology 3: 77-101.

Bryman, A. 2008. Social Research methods, Oxford: Oxford University Press.

Cialdini, R. 1991. "Crafting normative messages to protect the environment." Current Directions in Psychological Science 12: 105-109. 
Conradson, D. 2005. 'Focus groups' in Flowerdew, R. and Martin, D. (eds) Methods in Human Geography. Essex: Pearson.

Costran Broto, V. and Bulkeley, H. (2013) "A survey of urban climate change experiments in 100 cities." Global Environmental Change 23: 92-102.

Dancey, C., Reidy, J. and Rowe, R. 2012. Statistics for the Health Sciences: A Nonmathematical introduction. London: Sage.

Dietz, T., Gardner, G. T., Gilligan, J., Stern, P. C. and Vandenbergh, M. P. 2009. "Household actions can provide a behavioural wedge to rapidly reduce US carbon emissions." Proceedings of the National Academy of Sciences 106: 18452-18456.

Geels, F. W. 2002. "Technological transitions as evolutionary reconfiguration processes: A multilevel perspective and a case study." Research Policy 31: 1257-1274.

Geels, F. W. and Schot, J. 2007. "Typology of socio-technical transition pathways." Research Policy 36: 399-417.

Feola, G. and Nunes, R. 2014. "Success and failure of grassroots innovations for addressing climate change: The case of the Transition Movement." Global Environmental Change 24: 232-250.

Haxeltine, A. and Seyfang, G. 2009. Transitions for the People: Theory and Practice of 'Transition' and 'Resilience' in the UK's Transition Movement, Tyndall Working Paper 134: Tyndall Centre for Climate Change Research.

Kennedy, A. L. 2010. "Using community-based social marketing techniques to enhance environmental regulation" Sustainability 2: 1138-1160.

Kollmuss, A. and Agyeman, J. 2002. "Mind the Gap: Why do people act environmentally and what are the barriers to pro-environmental behaviour?." Environmental Education Research 8: 239-260.

Krause, K-L. and Coates, H. 2008. "Students' engagement in first-year university." Assessment and Evaluation in Higher Education 33: 493-505.

Lorenzoni, I., Nicholson-Cole, S. and Whitmarsh, L. 2007. "Barriers perceived to engaging with climate change among the UK public and their policy implications." Global Environmental Change 17: 445-459.

Mannarini, T. 2011. "Public involvement and competent communities: Towards a social psychology of public participation." International Journal of Humanities and Social Science 1: 66-72.

McCright, A. M. 2011. "Political orientation moderates Americans' beliefs and concern about climate change: An editorial comment." Climatic Change 104: 243-253.

McKillup, S. 2012. Statistics Explained. Cambridge: Cambridge University Press.

Medina, J. 2011. "Toward a Foucaultian Epistemology of Resistance: Counter-Memory, Epistemic Friction, and Guerrilla Pluralism." Foucault Studies 12: 9-35.

Middlemiss, L. 2011. "The effects of community-based action for sustainability on participants' lifestyles.” Local Environment 16: 265-280.

Middlemiss, L. and Parrish, B. D. 2010. "Building capacity for low-carbon communities: The role of grassroots initiatives.” Energy Policy 38: 7559-7566.

Moloney, S., Horne, R. E. and Fien, J. 2010. "Transitioning to low carbon communities - from behaviour change to systemic change: Lessons from Australia.” Energy Policy 38: 7614-7623.

Morgan, D. L. 1997. Focus Groups as Qualitative Research. London: Sage.

Morrison, C. and Dearden, A. 2013. "Beyond tokenistic participation: Using representational artefacts to enable meaningful public participation in health service design." Health Policy 112: 179-186. 
Mulugeeta, Y., Jackson, T. and van der Horst, D. 2010. "Editorial: Carbon Reduction at Community Scale." Energy Policy 38: 7541-7545.

Newing, H. 2011. Conducting Research in Conservation: A Social Science Perspective. Oxon: Routledge.

Ockwell, D., Whitmarsh, L. and O’Neill, S. 2009. "Reorienting Climate Change Communication for Effective Mitigation: Forcing People to be Green or Fostering Grassroots Engagement." Science Communication 30: 305-327.

Owens, S. and Driffill, L. 2008. "How to change attitudes and behaviours in the context of energy." Energy Policy 36: 4412-4418.

Rogers, J. C., Simmons, E. A., Convery, I. and Weatherall, A. 2008. "Public perceptions of opportunities for community-based renewable energy projects." Energy Policy 36: 4217-4226.

Roy, J. and Pal, S. 2009. "Lifestyles and climate change: Link awaiting activation." Current Opinion in Environmental Sustainability 1: 192-200.

Savin-Baden, M. and Howell Major, C. 2013. Qualitative Research: The essential guide to theory and practice. Oxon: Routledge.

Seyfang, G. 2010. "Community action for sustainable housing: Building a low-carbon future." Energy Policy 38: 7624-7633.

Seyfang, G. and Longurst, N. 2013. "Desperately seeking niches: grassroots innovations and niche development in the community currency field." Global Environmental Change 23: 881-891.

Seyfang, G., Hielscher, S., Hargreaves, T., Martiskainen, M. and Smith, A. 2014. "A grassroots sustainable energy niche? Reflections on community energy in the UK.", Environmental Innovation and Societal Transitions 13: 21-44.

Stern, P. and Dietz, T. 1999. "A value-belief-norm theory of support for social movements: The case of environmentalism." Research in Human Ecology 6: 81-97.

Verplanken, B. 2011. 'Old Habits and New Routes to Sustainable Behaviour' in Whitmarsh, L., O’Neill, S. and Lorenzoni, I. (eds) Engaging the Public with Climate Change: Behaviour Change and Communication. London: Earthscan.

While, A., Jonas, A. E. G. and Gibbs, D. 2010. "From sustainable development to carbon control: Eco-state restructuring and the politics of urban and regional development." Transactions of the Institute of British Geographers 35: 76-93.

Whitmarsh, L. 2009. "Behavioural responses to climate change: Asymmetry of intentions and impacts." Journal of Environmental Psychology 29: 13-23.

Whitmarsh, L. and O'Neill, S. 2011. 'Introduction: Opportunities for and Barriers to Engaging Individuals with Climate Change' in Whitmarsh, L., O'Neill, S. and Lorenzoni, I. (eds) Engaging the Public with Climate Change, London: Earthscan.

Whitmarsh, L., O'Neill, S. and Lorenzoni, I. 2013. "Public engagement with climate change: what do we know and where do we go from here?.” International Journal of Media \& Cultural Politics 9: 7-25.

Whitmarsh, L., Seyfang, G. and O’Neill, S. 2011. "Public Engagement with Carbon and Climate Change: To what extent is the public 'carbon capable'?" Global Environmental Change 21: 56-65.

Wiesenfeld, E. and Sanchez, E. 2002. 'Sustained Participation: A Community Based Approach to Addressing Environmental Problems' in Bechtel, R. B. and Churchman, A. (eds) Handbook of Environmental Psychology. New York: John Wiley \& Sons.

Winter, K. 2010. 'Why involve the public? Case studies of public involvement in environmental 
initiatives in South Africa' in Wilson, G., Furniss, P. and Kimbowa, R. (eds) Environment, Development and Sustainability. Oxford: Oxford University Press.

Wisker, G. 2001. The Postgraduate Research Handbook. Basingstoke: Palgrave.

Wolf, J. and Moser, S. C. 2011. "Individual understandings, perceptions, and engagement with climate change: insight from in-depth studies across the world." WIRES Climate Change 2: 547-569.

\section{Disclaimer:}

All of the participants who took part in the focus groups gave permission to use their direct quotes in this piece. 